\title{
O PERFIL DAS GESTORAS DA FEDERAÇÃO DO ESPÍRITO SANTO DE GINÁSTICA E AS PERSPECTIVAS ACERCA DA SUA GESTÃO
}

\author{
THE MANAGERS' PROFILE OF ESPÍRITO SANTO GYMNASTICS \\ FEDERATION AND THE PERSPECTIVES ABOUT THEIR MANAGEMENT
}

\section{EL PERFIL DE LOS DIRIGENTES DE LA FEDERACIÓN DEL ESPÍRITO SANTO DE GIMNASIA Y LAS PERSPECTIVAS SOBRE SU GESTIÓN}

\author{
Isabela Christ Maximo \\ https://orcid.org/0000-0002-5747-3592 ic \\ http://lattes.cnpq.br/8202515547852064 \\ Universidade Federal do Espírito Santo (Vitória, ES - Brasil) \\ isabela.christ@hotmail.com \\ Letícia Bartholomeu de Queiroz Lima \\ https://orcid.org/0000-0002-3570-7343 (D) \\ http://lattes.cnpq.br/1972028713208884 \\ Centro Universitário Herminio Ometto (Araras, SP - Brasil) \\ leticia_queiroz@hotmail.com \\ Myrian Nunomura \\ https://orcid.org/0000-0002-3669-0571 (iD \\ http://lattes.cnpq.br/0318875503554406 9 \\ Universidade de São Paulo (Ribeirão Preto, SP - Brasil) \\ mnunomur@usp.br \\ Maurício Santos Oliveira \\ https://orcid.org/0000-0002-4779-0092 (iD \\ http://lattes.cnpq.br/4786947482425420 9 \\ Universidade Federal do Espírito Santo (Vitória, ES - Brasil) \\ mauricio.s.oliveira@ufes.br
}

\section{Resumo}

A Ginástica do Brasil esteve sob os holofotes nas primeiras décadas do século XXI. No entanto, ao longo desse período, problemas relativos à gestão emergiram e ofuscaram, em parte, os resultados logrados. Essa problemática nos motivou a desenvolver esse estudo que teve como objetivo analisar a gestão e o perfil dos gestores da Federação do Espírito Santo de Ginástica. Para tanto, optamos pela abordagem de um estudo de caso. Constatamos que a Ginástica capixaba estava sob o comando de mulheres, presidente e vice-presidente, que possuíam um histórico de envolvimento com a Ginástica Artística e a Ginástica Rítmica, respectivamente. As dirigentes atuavam de forma voluntária e desenvolviam atividades que ultrapassavam os limites da sua formação profissional em Educação Física. Apesar dos desafios, emergiu no discurso das dirigentes a motivação para continuar o trabalho devido ao amor e o desejo de apoiar o desenvolvimento da Ginástica no Espírito Santo.

Palavras-chave: Gestão do Esporte; Organização Esportiva; Ginástica; Gestor Esportivo.

\section{Abstract}

Brazilian Artistic Gymnastics was spotlighted in the first decades of 21th century. However, throughout this period, problems related to the management of Brazilian gymnastics emerged and, partly, overshadowed the results achieved. This problem related to the management of Brazilian gymnastics motivated us to develop this study, which aims to analyze the management and the managers' profile of State Federation of Espírito Santo. Therefore, 
we chose the case study methodological approach. We noticed that the Gymnastics in Espírito Santo was under command of women, president and vice president, who had a history of involvement with Artistic Gymnastics and Rhythmic Gymnastics, respectively. The managers worked voluntarily and developed activities that exceeded the limits of their professional training in Physical Education. Despite the challenges, the motivation to continue the work emerged in the managers' discourse due to the love and the desire to support the development of Gymnastics in Espírito Santo.

Keywords: Sports Management; Sports Organization; Gymnastics; Sport Manager.

\section{Resumen}

La Gimnasia de Brasil estuvo en punto de destaque en las primeras décadas del siglo 21. Sin embargo, a lo largo de este período, problemas relacionados con la administración surgieron y obscurecieron, en parte, los resultados logrados. Esta problemática nos motivó a desarrollar este estudio, que tiene como objetivo analizar la gestión y el perfil de los administradores de la Federación de Gimnasia del Espírito Santo. Metodológicamente, elegimos un estudio de caso. Observamos que la Gimnasia de Espírito Santo estaba bajo el mando de mujeres, presidenta y vicepresidenta, que tenían un record de participación con Gimnasia Artística y Gimnasia Rítmica, respectivamente. Las administradoras trabajaron voluntariamente y desarrollaron actividades que excedían los límites de su formación profesional en Educación Física. A pesar de los desafíos, constatamos la motivación de las administradoras en seguir el trabajo debido al amor y el deseo de apoyar el desarrollo de la Gimnasia en Espírito Santo.

Palabras clave: Gestión Deportiva; Organización Deportiva; Gimnasia; Administradores Deportivos.

\section{INTRODUÇÃO}

Piekarz (2009) analisa que muitas pessoas falham em perceber a importância que a indústria do Esporte adquiriu no mundo contemporâneo. A autora destaca que o Esporte é um negócio que emprega milhões de pessoas, gera grande quantidade de recursos financeiros, serve como instrumento político e, assim, incide na qualidade de vida de muitos indivíduos.

Com esse crescimento e abrangência, a administração de instituições esportivas adquiriu importância proeminente, principalmente, aquelas orientadas ao esporte com vista ao alto rendimento, o que acarretou a necessidade de que a gestão do esporte seja exercida por profissionais competentes capazes de catalisar a excelência nos campos esportivo e administrativo (MATTAR; MATTAR, 2013).

Capinussú (2002) cita que na década de 1970, mais especificamente após a conquista do tricampeonato na Copa do Mundo, o treinador Flávio Costa afirmou que o futebol brasileiro apresentava uma grande progressão que emergia da boca do túnel para dentro de campo, mas que fora das quatro linhas a desorganização permanecia. Bastos (2003), ao analisar a obra Diagnóstico da Educação Física/Desportos no Brasil (COSTA, 1971), alude que naquele período já era perceptível o desenvolvimento da indústria do esporte no que concerne aos materiais esportivos, construções e instalações para as práticas e treinamentos, mas não havia menção às questões de gestão do esporte. 
A partir da demanda do mercado, impulsionado pelo desenvolvimento da indústria esportiva naquele período da década de 1970, observamos a emergência de programas de formação em gestão do esporte no Brasil. Bastos (2003) destaca o curso realizado na Escola de Educação Física da Universidade de São Paulo em 1978, o qual foi um marco para a área no contexto brasileiro, sendo sucedido pela oferta de disciplinas, de cursos de curta e de longa duração e que foram organizados, desde aquele momento até os dias de hoje, por Universidades, faculdades, sindicados e entidades profissionais.

Nesse sentido, observamos que ações formativas foram realizadas na área da gestão do esporte, inclusive organizadas pelo Comitê Olímpico do Brasil no contexto contemporâneo (COB, 2021). Mas, corroboramos Bastos (2003) que apenas a participação em cursos que repassam e discutem os conceitos básicos da área não são suficientes, principalmente, devido às demandas atuais da indústria do esporte. Ademais, Mazzei, Amaya e Bastos (2013) alertam para as lacunas na formação do gestor do esporte no Brasil, independentemente do formato do curso, bem como na oferta dos mesmos.

Essa questão formativa incide diretamente na atuação daqueles que estão à frente das organizações esportivas e o sucesso de ligas competitivas, clubes e associações dependem de indivíduos capacitados dentro e, também, fora de campo. Corroboramos Bastos (2003) que o desenvolvimento de algumas modalidades no Brasil foi influenciado de forma preponderante pelo desempenho da gestão do esporte, como é o caso do voleibol. $E$, o êxito de organizações esportivas está diretamente ligado às ações dos indivíduos que as compõem (HUMS; MACLEAN, 2004), o que aumenta a necessidade de formação específica que atenda às relações complexas que permeiam a gestão do esporte.

A partir da reflexão do ex-treinador da seleção brasileira Flávio Costa (CAPINUSSÚ, 2002), salvaguardando as diferenças entre as modalidades, podemos nos questionar se a gestão da Ginástica do Brasil é condizente com os resultados proeminentes dos ginastas brasileiros, os quais foram conquistados nas primeiras décadas que marcaram o início do século XXI.

Ao analisarmos as conquistas da Ginástica brasileira em Jogos Olímpicos, observamos que na edição do Rio de Janeiro em 2016, a ginástica do Brasil foi representada nas três modalidades do programa olímpico e conquistou três pódios na competição. As medalhas de prata dos atletas Diego Hypólito e Arthur Zanetti, assim como o bronze do Arthur Nory, colocaram a Ginástica Artística (GA) em um novo patamar. Compete rememorar 
que o ginasta Arthur Zanetti foi campeão olímpico em Londres 2012. E, mais recentemente, a ginasta Rebeca Andrade logrou duas medalhas, ouro e prata, nos Jogos de Tóquio 2020.

Apesar desse grande sucesso, observamos que o êxito dos(as) atletas foi ofuscado por problemas administrativos da Confederação Brasileira de Ginástica (CBG), os quais emergiram antes e após esses megaeventos esportivos. Problemas na transparência da gestão, pagamento de salários acima do mercado, remuneração duplicada de serviços e problemas relacionados à compra de equipamentos foram noticiados pela mídia esportiva nacional fundamentada nos pareceres do Tribunal de Contas da União (GARCIA; VALENTE, 2017; LIMA, 2020; CASTRO, 2021).

Concordamos com Mattar e Mattar (2013) que, para que haja desenvolvimento contínuo e eficaz do esporte, seria necessário e fundamental que a administração esportiva fosse profissional, tanto na esfera pública quanto privada, e que contemplasse os níveis governamentais (federal, estadual e municipal), as estruturas de poder (ligas, federações e confederações) e as instituições esportivas onde é praticado (clubes, escolas, empresas, prefeituras, projetos sociais). Observamos no cenário nacional da gestão de instituições esportivas que a evolução em direção à profissionalização é lenta e está aquém quando comparada às potências esportivas internacionais (BASTOS; MAZZEI, 2015). Mattar e Mattar (2013) e Barros e Mazzei (2012) afirmam que a gestão do esporte no Brasil ainda se encontra em estágio amador. Os autores destacam que há raras exceções e que isso incide no desenvolvimento pleno do esporte nacional.

Nesse sentido, Capinussú (2002) alude que o reflexo dessa desorganização na gestão do esporte brasileiro pode ser sentido no momento em que os(as) atletas participam nas competições, pois "aquela paz interior que técnicos e atletas tanto necessitam para desempenhar com êxito seu papel deixa de existir, pois uns e outros passam a se preocupar com problemas atinentes à falta de verbas, casos disciplinares, apoio logístico deficiente, entre os mais comuns" (CAPINUSSÚ, 2002, p. 13). Evidencia-se a ausência de uma retaguarda competente, constituída de gestores(as) capazes de tomar a si a solução de tais problemas. Enfim, falta material humano em quantidade e, principalmente, qualidade, para atender a demanda que o mercado impõe.

Corroboramos Capinussú (2002) que o planejamento, organização, execução e controle de programas de gestão do esporte, em nível de clubes, federações e órgãos estatais são atividades complexas. $E$, aqueles(as) que as desempenham precisam de 
conhecimento especializado para propiciar o seguimento destes princípios de forma disciplinada e coerente (AMARAL; BASTOS, 2015; ZANATTA et al., 2018).

Tendo em vista essa problemática, assim como o número reduzido de estudos sobre o perfil de gestores(as) esportivos no Brasil e a necessidade de pesquisas nesta vertente apontada por Amaral e Bastos (2015), o objetivo desse estudo foi analisar a gestão da ginástica espírito-santense e o perfil das gestoras que administram essa entidade, as quais: presidente e vice-presidente. Acreditamos que o diagnóstico do perfil das gestoras que atuam na Federação do Espírito Santo de Ginástica (FESG), bem como aspectos relacionados à gestão, podem nos auxiliar a compreender e propor ações que auxiliariam a enfrentar problemas que incidem no desenvolvimento das modalidades gímnicas no âmbito estadual e, consequentemente, nacional. Ademais, corroboramos Azevedo, Barros e Suaiden (2004) que a gestão do esporte carece de investigações contínuas, a qual apresenta lacunas que precisam ser preenchidas pela produção de conhecimento. Trata-se de tema atual e relevante, principalmente, numa sociedade que cada vez mais exige transparência e competência no trato de questões administrativas que envolvem o uso de recursos públicos.

\section{METODOLOGIA}

Dentre os tipos de pesquisa de campo, optamos pelo estudo de caso que "visa à investigação de um caso específico, bem delimitado, contextualizado em tempo e lugar para que se possa realizar uma busca circunstanciada de informações" (VENTURA, 2007, p. 384).

Para a coleta dos dados, optamos pela técnica da entrevista semiestruturada, a qual foi implementada com as colaboradoras do estudo que foi constituída pelas gestoras da FESG, mandato 2017-2020, sendo: presidente e vice-presidente. Utilizaremos uma sigla devido às possíveis implicações políticas e administrativas dos assuntos abordados na pesquisa. Assim, utilizamos a sigla G (gestora) seguida de uma numeração (Exemplo: G1) para efeito de organização.

Para a análise das entrevistas, recorremos à Análise de Conteúdo de Bardin (2011). De acordo a autora, os dados são codificados, classificados e categorizados, processo que torna possível uma análise sobre as mensagens que emergem do conteúdo e que se referem aos pontos de interesse para a pesquisa (BARDIN, 2011). 
Dentre as várias possibilidades de categorização, objetivamos uma análise temática que "consiste em descobrir núcleos de sentido que compõem a comunicação e cuja presença, ou frequência de aparição podem significar alguma coisa para o objetivo analítico escolhido" (BARDIN, 2011, p. 135). Esse procedimento permitiu a construção de quadros de resultados com o objetivo de condensar e revelar as informações fornecidas pela análise (BARDIN, 2011), o que favoreceu a inferência e a interpretação dos resultados de acordo com os objetivos estabelecidos.

\section{RESULTADOS E DISCUSSÃO}

Destinada a reunir as entidades desportivas que possuem o interesse na prática da Ginástica no estado do Espírito Santo, a FESG tem como um de seus objetivos "promover a realização de Campeonatos, Avaliações, Festivais, Cursos, Pesquisa, Intercâmbio e qualquer outro ato que objetive o desenvolvimento e fomento da Ginástica Estadual" (FESG, 2019, p. 1) e abrange, em âmbito estadual, o que diz respeito à Ginástica Escolar, Universitária, de Clubes e entre Entidades Filiadas (FESG, 2019).

Nesse contexto, observamos que a importância do(a) gestor(a) esportivo(a) aumenta e, na mesma proporção, cresce a necessidade de profissionais cada vez mais especializados, qualificados (BARROS FILHO et al., 2013). Torna-se pertinente conceituar que Mullin (1980), já na década de 1980, definia o(a) gestor(a) esportivo(a) como o indivíduo cujo trabalho e atuação abrangiam o planejamento, a organização, o direcionamento e o controle de ações realizadas no contexto das organizações esportivas, no qual o produto ou serviço primário ou predominante era o esporte ou relacionado a esse fenômeno. Pires e Lopes (2001), ao analisarem diferentes estudos internacionais, pontuam que a gestão do esporte se consolida como uma área de intervenção profissional que provoca uma série de aproximações de ideias políticas, estratégicas e pedagógicas que, na concepção dos autores, orientam o esporte no geral e das instituições esportivas em particular.

No caso da FESG, compete ao(à) gestor(a) esportivo(a) o ato de "supervisionar, coordenar, dirigir e fiscalizar as atividades administrativas, econômicas, financeiras e desportivas" (FESG, 2019, p. 5), com o fim de promover as diferentes formas de ginástica no estado. $E$, ao analisarmos o perfil das gestoras que ocupam a função de presidente e vicepresidente da FESG, observamos que ambos os cargos são ocupados por mulheres. 
Zanatta e colaboradores (2018) alertam para o baixo índice de representação das mulheres nos quadros administrativos. Gomes (2005) destaca o percentual de $6,5 \%$ da participação de mulheres em federações estaduais. No entanto, os dados aqui obtidos vão de encontro à análise de Gomes (2005) ao apontar que das federações esportivas analisadas até o ano de 2004 apenas 7\% eram presididas por mulheres e estas sendo na maioria federações de Ginástica.

No que concerne à idade das gestoras capixabas, verificamos que G1 possui 30 anos e G2 54. Destarte, salvaguardando as diferenças, esse escore está dentro da média dos dados encontrados na literatura que indicam um valor médio de no mínimo 32,8 anos e de no máximo 57 anos (COUTO et al. 2011; ZANATTA et al., 2018). Concordamos com Barros Filho e colaboradores (2013) que o perfil profissional dessa classe é jovem com possibilidade de crescer em termos de conhecimento e experiência no decorrer do tempo.

No Quadro 1, verificamos o envolvimento prévio das gestoras com o intuito de averiguar se a origem desse relacionamento com a ginástica pode ter contribuído na decisão de se enveredar no universo da gestão do esporte.

Quadro 1 - Categoria: envolvimento com a ginástica

\begin{tabular}{|c|l|}
\hline Unidade de Registro & \multicolumn{1}{|c|}{ Unidade de Contexto } \\
\hline Atleta & $\begin{array}{l}\text { G1: "Fui atleta por mais ou menos 12 a 15 anos de alto } \\
\text { rendimento [...]". }\end{array}$ \\
\hline Técnica & G2: "Eu sou professora de escolinha de esporte [...]". \\
\hline
\end{tabular}

Fonte: construção dos autores.

Nas respostas das participantes do estudo, constatamos que uma das gestoras foi ginasta de alto rendimento na modalidade GA. Tal perfil vai ao encontro da literatura, que aponta que a maioria dos(as) gestores(as) foram ex-praticantes de modalidades esportivas (ZANATTA et al., 2018). No caso de G2, essa teve sua origem na dança e, posteriormente, se envolveu com o treinamento de Ginástica Rítmica (GR) e formou ginastas que compuseram a seleção brasileira. Compete destacar que a irmã de $G 2$ foi ginasta da $G R$, o que auxiliou a estreitar os laços da gestora com a modalidade e a sua inserção profissional no meio gímnico.

Embora consideremos que esse contato e experiência prévia com a ginástica sejam importantes, concordamos com Zannata e colaboradores (2018) que essa experiência 
não dispensa a necessidade da formação específica para atuar nas atividades que a gestão requer. Ponderamos que a experiência prévia facilitaria a inserção nesse meio devido à familiarização e, também, colaboraria para uma perspectiva mais ampla dos problemas e ações a serem desenvolvidas no cotidiano da federação (ZANATTA et al., 2018). Mas, isso não isentaria a necessidade de se preparar o(a) gestor(a) em relação às competências específicas da gestão que a vivência como treinador(a) ou ex-atleta não proporcionaram. Esse envolvimento prévio influenciou, em certa medida, a seleção para o cargo (Quadro 2) que ocorreu, no caso de G1, por convite e, para G2, por indicação.

Quadro 2 - Categoria: seleção para o cargo

\begin{tabular}{|c|l|}
\hline Unidade de Registro & \multicolumn{1}{c|}{ Unidade de Contexto } \\
\hline Convite & $\begin{array}{l}\text { G1: "Na verdade, eu fui convidada [...]. Eu aceitei mais pelo fato } \\
\text { de ter o apoio [...]". }\end{array}$ \\
\hline Indicação & $\begin{array}{l}\text { G2: "O meu foi indicação mesmo. [...] e me indicaram por eu me } \\
\text { dar bem com todos". }\end{array}$ \\
\hline
\end{tabular}

Fonte: construção dos autores.

G1 destaca que o convite para o cargo de gestão ocorreu por meio de membros dos Comitês Técnicos da GA e da GR que tinham a intenção de apoiar uma chapa com a presença de indivíduos que atuavam nessas modalidades. A atuação de G1 como ginasta, treinadora e árbitra de GA foram fatores ponderados para o estabelecimento desse convite. Esse apoio foi importante para que G1 aceitasse concorrer ao cargo. Com relação à G2, foi perceptível que, além da atuação da gestora na GR, como treinadora e árbitra, o fato dela ter bom convívio com todos foi decisivo.

Isayama e colaboradores (2011) se respaldam na concepção de que as relações e as escolhas políticas são baseadas na representação de interesses múltiplos e que isso afeta os cidadãos envolvidos. Esse aspecto foi evidenciado em nosso estudo pela atuação dos membros dos Comitês Técnicos e de membros da gestão anterior. Destacamos que tanto G1 quanto G2 não tinham a intenção de atuar na gestão da federação. Mas, em ambas as respostas, ficou evidente que o apoio da comunidade e o interesse em contribuir com a organização da ginástica capixaba foram aspectos essenciais para a decisão. Com a intenção de aprofundar o conhecimento sobre a motivação para exercer o cargo de gestão, questionamos as participantes do estudo acerca disso (Quadro 3). 
Quadro 3 - Categoria: motivação para exercer a função de gestão

\begin{tabular}{|c|c|l|}
\hline Subcategoria & Unidade de Registro & \multicolumn{1}{|c|}{ Unidade de Contexto } \\
\hline $\begin{array}{c}\text { Motivação } \\
\text { Extrínseca }\end{array}$ & Trabalho em conjunto & $\begin{array}{l}\text { G1: "Então essa questão da divisão certinha } \\
\text { dentro da federação, eu acho que foi o que } \\
\text { me deu mais vontade de trabalhar [...]". }\end{array}$ \\
\hline $\begin{array}{c}\text { Motivação } \\
\text { Intrínseca }\end{array}$ & Amor pela ginástica & $\begin{array}{l}\text { G2: "O amor pela ginástica! Não tem } \\
\text { explicação". }\end{array}$ \\
\hline
\end{tabular}

Fonte: construção dos autores.

A resposta de G1 está relacionada aos aspectos supracitados, ou seja, sobre a seleção para o cargo (Quadro 2). A gestora destaca que a possibilidade de trabalhar em equipe foi determinante para a decisão. Já G2, alude ao seu amor pela ginástica como aspecto motivacional para assumir o cargo de gestão do esporte: "A gente quer ajudar, não importa a forma e queremos que a ginástica cresça". Além disso, G2 afirma que também temia que alguém sem experiência pudesse assumir o cargo e prejudicasse 0 desenvolvimento das modalidades: "Então, eu fiquei com receio de que assumisse uma pessoa que fosse acabar com a ginástica".

A preocupação de que alguém sem experiência pudesse assumir a presidência pode estar relacionada ao inciso 5. do Estatuto da federação (FESG, 2019) que destaca que caso não haja chapa composta por pessoas habilitadas e qualificadas no prazo de 60 dias antes da eleição, uma chapa que não atenda a esses preceitos poderá ser inscrita. No Quadro 4, podemos acompanhar os aspectos relacionados à formação profissional das participantes do estudo.

Quadro 4 - Categoria: formação profissional

\begin{tabular}{|c|c|}
\hline $\begin{array}{c}\text { Unidade de Registro } \\
\text { Graduação em } \\
\text { andamento }\end{array}$ & G1: "[...] estou terminando o curso de educação física". \\
\hline Pós-graduação & G2: "Eu sou pós-graduada em educação física escolar". \\
\hline
\end{tabular}

Fonte: construção dos autores.

Parkhouse (1996), ao analisar a formação dos(as) gestores(as) esportivos(as), disserta que essa tem sido fundamentada em cursos de graduação e de especialização em dois pilares, os quais: Educação Física e Administração. Isso coincide com o apontamento de Zanatta e colaboradores (2018), de que a maioria dos(as) gestores(as) brasileiros(as) é graduado(a) em Educação Física. Especificamente, no nosso estudo, verificamos que G1 e G2 
seguem esse perfil formativo hegemônico, pois ambas buscaram a formação em Educação Física.

Corroboramos Barros Filho e colaboradores (2013) que o profissional de Educação Física conquistou o seu espaço na gestão do esporte no Brasil, o qual está amparado pela Lei 9.696 que, no 3. Artigo, alude que

Compete ao Profissional de Educação Física coordenar, planejar, programar, supervisionar, dinamizar, dirigir, organizar, avaliar e executar trabalhos, programas, planos e projetos, bem como prestar serviços de auditoria, consultoria e assessoria, realizar treinamentos especializados, participar de equipes multidisciplinares e interdisciplinares e elaborar informes técnicos, científicos e pedagógicos, todos nas áreas de atividades físicas e do desporto (BRASIL, 2021).

Ainda de acordo com a Lei 9.696, salientamos que o "O exercício das atividades de Educação Física e a designação de Profissional de Educação Física é prerrogativa dos profissionais regularmente registrados nos Conselhos Regionais de Educação Física" (BRASIL, 2021).

No entanto, sabemos que os conhecimentos obtidos na graduação não são suficientes para atender as demandas da gestão do esporte na atualidade. Há a necessidade de aprofundamento, que pode ser obtido em cursos de formação continuada de curta e de longa duração. Cientes disso, questionamos as participantes do estudo sobre a preparação para assumir o cargo após a eleição (Quadro 5).

Quadro 5 - Categoria: preparação para o cargo de gestão

\begin{tabular}{|c|l|}
\hline Unidade de Registro & \multicolumn{1}{c|}{ Unidade de Contexto } \\
\hline Treinamento & $\begin{array}{l}\text { G1: "Não [...] é muito na cara e na coragem!". } \\
\text { G2: "Não, nenhuma. Só aprendemos mesmo no dia a dia". }\end{array}$ \\
\hline
\end{tabular}

Fonte: construção dos autores.

Tanto G1 quanto G2 afirmaram que não houve a realização de treinamento ou curso que as preparassem para a atuação na gestão da FESG. É pertinente destacar que G2 citou o apoio da ex-presidente que lhe ensinou algumas coisas, mas nas palavras da gestora: "o restante, eu quebro a cabeça tentando aprender". O desafio de "aprender no dia a dia" da atividade de gestão é grande em virtude do número de atribuições. Bastos (2003) afirma que a administração esportiva envolve o emprego de conceitos e teorias gerais da administração do esporte, assim como o papel que o fenômeno esportivo exerce na sociedade. E, ademais, o estudo da área inclui conhecimento multidisciplinar e que, segundo Nolasco e 
colaboradores (2005, p. 760), é constituída por "um corpo de conhecimento interdisciplinar que se relaciona com a direção, liderança e organização do esporte, incluindo dimensões comportamentais, ética, marketing, comunicação, finanças, economia, negócios em contextos sociais, legislação e preparação profissional".

Em complementação, Gomes (2001) expõe que os(as) gestores(as) têm a função de organizar, definir os objetivos, promover as atividades e assegurar o funcionamento e o futuro da própria organização. Assim, podemos inferir que o(a) gestor(a) esportivo(a) possui uma gama de atribuições que fica evidente nos discursos de G1 e G2 (Quadro 6).

Quadro 6 - Categoria: principais atividades no cargo

\begin{tabular}{|l|l|}
\hline Unidade de Registro & \multicolumn{1}{c|}{ Unidade de Contexto } \\
\hline Organização de tudo & $\begin{array}{l}\text { G1: "Eu praticamente faço o auxílio de tudo [...]". } \\
\text { G2: "Organizar os eventos [...]. A gente organiza também o uso } \\
\text { dos ginásios [...] também tem a parte financeira que é aí que pega } \\
\text { com as prestações de conta". }\end{array}$ \\
\hline
\end{tabular}

Fonte: construção dos autores.

No caso da FESG ficou perceptível que as gestoras lidam com aspectos que vão desde a manutenção das estruturas físicas, sede da entidade e ginásios cedidos em parcerias com o setor público, até a organização dos aspectos financeiros. Tanto G1 quanto G2 enfatizaram a organização de festivais, copas, torneios e campeonatos como a principal atividade exercida na gestão. Embora o rol de atividades seja amplo, ambas atuam de forma voluntária e não recebem qualquer auxílio financeiro (Quadro 7).

Quadro 7 - Categoria: remuneração

\begin{tabular}{|c|l|}
\hline Unidade de Registro & \multicolumn{1}{|c|}{ Unidade de Contexto } \\
\hline \multirow{3}{*}{ Pagamento } & G1: "Não, nadinha [...] só dor de cabeça". \\
& $\begin{array}{l}\text { G2: "Sim, tudo voluntário. Eu não posso tirar dinheiro da } \\
\text { federação nem pra transporte". }\end{array}$ \\
\hline
\end{tabular}

Fonte: construção dos autores.

O discurso de G2 evidencia que nem as despesas oriundas do exercício da função são restituídas, ou seja, compete ao(à) gestor(a) arcar com esses gastos que são inevitáveis no cotidiano da federação. Gomes (2001) sintetiza bem essa questão ao dizer que os(as) gestores(as): 
[...] em regime de benevolato, dedicam largas horas do seu tempo às tarefas de gestão de clubes e associações desportivas, para que crianças, jovens e adultos possam praticar uma actividade desportiva, abdicando, por vezes, de maiores desempenhos nas actividades profissionais e ao convívio familiar ( $p$. 62).

Essa situação financeira vai em direção contrária ao que se espera de uma gestão profissional, pois, conforme Pimenta (2001, p. 9), "o ambiente esportivo necessita cada vez mais de um quadro técnico, formado por profissionais capacitados e gabaritados das diversas áreas envolvidas nesse setor, incluindo-se o gerencial". Ainda segundo o autor, "aquela prática voluntariosa sustentada na boa vontade e no amadorismo deixou de ser o modelo operacional" (PIMENTA, 2001, p. 10). Essa afirmação está alinhada ao pensamento de Ribeiro (2012) e Barros e Mazzei (2012) que destacam que a indústria do esporte no Brasil é gerida, entre outros, por entidades privadas sem fins lucrativos, dentre elas as federações, que são comandadas em sua maioria por gestores(as) amadores(as) e voluntários(as) que ocasionam problemas de eficiência. Bastos e Mazzei (2020, p. 64), ao se referirem ao setor privado sem fins lucrativos "[...] destacam as organizações voluntárias que atuam em prol de causas sociais, de interesses específicos ou necessidades de seus membros. Pessoas eleitas por seus membros, com mandato determinado, atuam em comitês executivos e na diretoria, estabelecendo a gestão estratégica". Fatos estes que, consequentemente, afastam investidores e indicam a necessidade de profissionalização da gestão do esporte no âmbito das federações, assim como a necessidade de processos de avaliação e acompanhamento contínuos.

No Quadro 8, sintetizamos as respostas relativas às perspectivas para a organização da ginástica em longo prazo.

Quadro 8 - Categoria: perspectivas acerca da organização da ginástica

\begin{tabular}{|c|l|}
\hline Unidade de Registro & \multicolumn{1}{|c|}{ Unidade de Contexto } \\
\hline \multirow{2}{*}{$\begin{array}{c}\text { Parcerias com o setor } \begin{array}{l}\text { G1: "[..] ir às prefeituras e, de repente, [...] tentar colocar polos de } \\
\text { público }\end{array} \\
\text { ginástica. Isso movimentaria melhor o esporte no estado em } \\
\text { geral". }\end{array}$} \\
\cline { 2 - 2 } & $\begin{array}{l}\text { G2: "[...] esse envolvimento político acaba tendo algumas } \\
\text { facilidades, acordos, parcerias, enfim, cada um tem o seu lado e aí } \\
\text { tem uma facilidade.". }\end{array}$ \\
\hline
\end{tabular}

Fonte: construção dos autores. 
É perceptível que as gestoras, ao serem questionadas sobre as perspectivas de organização da ginástica no estado, remeteram aos fatores políticos do meio esportivo. Bastos e Mazzei (2015) citam que nos últimos anos houve o aumento gradativo da importância das políticas públicas do esporte, o qual se reflete na elaboração de Leis, na criação do Ministério do Esporte e no número de pesquisas realizadas na área. Nesse percurso, observamos que o apoio de políticas públicas consistentes seria o ideal para uma estrutura esportiva de sucesso (BARROS; MAZZEI, 2012). Devemos ponderar, fundamentados em Pimenta (2001, p. 78), que "é evidente que falta ao país uma clara política de desenvolvimento do esporte, mas existe também uma acomodação por parte da grande maioria das entidades de administração de não querer sair debaixo do "guarda-chuva" do Poder Público".

No caso do nosso estudo, observamos que o apoio dos municípios e do estado seja necessário para a cessão e manutenção das estruturas esportivas utilizadas pela FESG e, também, por meio das leis que incentivam o esporte de base e de alto rendimento. No decorrer da entrevista, não verificamos a busca por parcerias com o setor privado.

Quando questionamos o relacionamento entre a FESG e a CBG, verificamos que ele é visto como distante. No entanto, G2 considera ser positivo (Quadro 9).

Quadro 9 - Categoria: relação com a CBG

\begin{tabular}{|c|l|}
\hline $\begin{array}{c}\text { Unidade de Registro } \\
\text { Relacionamento } \\
\text { distante }\end{array}$ & $\begin{array}{l}\text { G1: "A presidente eu sei que vai na assembleia, que normalmente } \\
\text { é no começo do ano. E, depois disso, acredito que só em tópicos } \\
\text { bem específicos". }\end{array}$ \\
\hline Bom relacionamento & G2: "É boa". \\
\hline
\end{tabular}

Fonte: construção dos autores.

A fala de G1 sinaliza que o distanciamento se deve ao pouco contato ao longo do ano, o qual se restringe no encontro durante a Assembleia Geral da entidade. A oportunidade de ter ido como chefe de delegação em uma Copa do Mundo emergiu no posicionamento de G2 sobre esse assunto: "Eu fui chamada em setembro para ir como chefe de delegação na Copa do Mundo. Eles pagaram tudo para eu ir. Sinal que é uma boa relação". No entanto, podemos inferir que mesmo com esse sinal de "boa relação", o depoimento de G1 é mais condizente com o fato de não haver visitas ou encontros periódicos com a CBG. Essa relação observada vai ao encontro do apontamento de Lima 
(2020), em que a relação das federações de ginástica no país com a CBG ocorre, em sua maioria, apenas por meio de filiação para participação em campeonatos e eventos. $E$, da mesma forma, não observamos a preocupação no acompanhamento das ações federativas. Essas questões podem ser complementadas com os dados relativos ao suporte oferecido pela CBG (Quadro 10).

Quadro 10 - Categoria: suporte da CBG

\begin{tabular}{|c|l|}
\hline Unidade de Registro & \multicolumn{1}{|c|}{ Unidade de Contexto } \\
\hline Esporádico & $\begin{array}{l}\text { G1: "Nada. Só se eles acharem que nós estamos dando } \\
\text { problema". }\end{array}$ \\
\hline Apoio financeiro & $\begin{array}{l}\text { G2: "A CBG, esse ano, recebeu o patrocínio da CAIXA que foi } \\
\text { repassado } \$ 1000,00 \text { por } 8 \text { meses. }\end{array}$ \\
\hline
\end{tabular}

Fonte: construção dos autores.

Segundo G1, o apoio é esporádico e ocorreria se houvesse um problema. Já G2 cita o repasse financeiro ao longo de 8 meses que auxiliou no pagamento de despesas como o aluguel da sede da federação e as contas de manutenção desse espaço. Mas, destacamos que esse repasse não cobre todos os meses do ano e foi iniciado nessa metade de ciclo olímpico como apontado pela G2. Não evidenciamos, nos depoimentos de G1 e G2, o suporte por meio de cursos ou consultoria que pudessem apoiar o trabalho das gestoras. Essa ausência de apoio pode incidir nos fatores destacados como desafios da gestão (Quadro 11).

Quadro 11 - Categoria: desafios da gestão

\begin{tabular}{|c|l|}
\hline Unidade de Registro & \multicolumn{1}{c|}{ Unidade de Contexto } \\
\hline $\begin{array}{c}\text { Organização de } \\
\text { eventos }\end{array}$ & $\begin{array}{l}\text { G1: "Hoje é justamente esse. Da gente tentar fazer (os eventos). } \\
{[\ldots] \text { Os eventos da GA eram mal organizados. Tinha evento que }} \\
\text { durava seis horas [...]". }\end{array}$ \\
$\begin{array}{l}\text { G2: "Os eventos de grande porte [...]. O evento começou a ser } \\
\text { montado na segunda, sem dinheiro nenhum [...]". }\end{array}$ \\
\hline
\end{tabular}

Fonte: construção dos autores

Ambas as gestoras explicitaram em seus discursos que o grande desafio está vinculado aos eventos. Rubio (2007) reflete que não basta o Brasil organizar megaeventos esportivos se não realizamos, de forma adequada, os pequenos e normais do dia-a-dia, ou seja, os(as) gestores(as) necessitam de apoio no planejamento, implementação, avaliação e prestação de contas dos eventos locais, regionais e estaduais, para além daqueles 
organizados em âmbito nacional e internacional. Concordamos com Rubio (2007) que se queremos ter padrões regulares de eficiência e segurança nos níveis internacionais, devemos operar os eventos e ações menores com excelência. G2 expõe que o desafio está na captação de recursos e nas promessas de repasse público que são cancelados quando o evento está prestes a ocorrer.

No Quadro 12, expomos os pontos fracos e fortes da gestão na opinião das participantes. Um dos pontos fracos, enunciado por G2, está relacionado à falta de apoio. É perceptível que as demandas recaiam sobre os(as) gestores(a), treinadores(as) e, até mesmo, os pais dos(as) ginastas.

Quadro 12 - Categoria: pontos fortes e fracos da gestão

\begin{tabular}{|c|c|l|}
\hline Subcategoria & Unidade de Registro & \multicolumn{1}{c|}{ Unidade de Contexto } \\
\hline \multirow{3}{*}{ Pontos fortes } & As modalidades & $\begin{array}{l}\text { G1: "[...] os pontos fortes que a gente tem é a } \\
\text { modalidade [...]". }\end{array}$ \\
\cline { 2 - 4 } Pontos fracos & Os clubes & $\begin{array}{l}\text { G2: "[..] a parceria da federação com os clubes } \\
\text { que nós temos aqui no estado [...]". }\end{array}$ \\
\hline Confusões internas & $\begin{array}{l}\text { G1: "[..] muitas confusões internas na ginástica } \\
\text { com os clubes e a CBG. E acredito que se } \\
\text { chamassem todos os clubes ou as federações pra } \\
\text { darem mais opiniões [...] seria melhor, com mais } \\
\text { comprometimento". }\end{array}$ \\
\cline { 2 - 4 } & Falta de apoio & $\begin{array}{l}\text { G2: "A falta de apoio eu acho que é um ponto } \\
\text { fraco, pois é tudo em cima do técnico, do } \\
\text { professor, dos pais". }\end{array}$ \\
\hline
\end{tabular}

Fonte: construção dos autores.

Além da falta de apoio, G1 pontua as confusões internas como um ponto fraco e que poderiam ser sanadas com a maior participação dos clubes e federações nas ações da CBG. Segundo Oliveira (2010), a estrutura da ginástica no Brasil segue o modelo de organização esportiva internacional, a qual é hierarquizada e vertical. Assim, na base da estrutura da ginástica capixaba estão os clubes/associações/academias que são organizados pela FESG que, por conseguinte, é vinculada à CBG que está subordinada à FIG. Nesse percurso, muitas decisões são tomadas nas estruturas superiores dessa pirâmide organizacional e, assim, os clubes/associações/academias que estão na base não tem o poder de decisão. Conforme Boudens (2002), se seguirmos a lógica da legislação civil, o ideal 
seria a ordem inversa, ou seja, essa lógica está invertida no esporte institucionalizado em que as normas são ditadas do topo da hierarquia para a base.

Dentre os aspectos positivos, o potencial de desenvolvimento das modalidades e o apoio dos clubes são relacionados pelas gestoras com os pontos fortes da gestão. É pertinente mencionar que, no ano de 2019, a ginasta Natália Gaudio conquistou a medalha de bronze nos Jogos Pan-americanos na GR e quatro medalhas no Campeonato Sulamericano. No âmbito nacional, enaltecemos os resultados de Thais Lourencini na categoria juvenil da GR que conquistou um bronze e uma prata no Campeonato Brasileiro (CBG, 2019). E, no adulto, a Escola de Campeãs e o Clube Ítalo Brasileiro lograram a prata e o bronze, respectivamente, na disputa por equipes. Ademais, Natália Gaudio e Geovanna da Silva colocaram o Espírito Santo no pódio desta competição no individual (CBG, 2019).

Esses resultados citados facilitam a compreensão das respostas de G1 e G2 com relação aos pontos positivos. No entanto, é perceptível que apenas a GR exibe resultados proeminentes. Após todas essas informações, nas quais discutimos alguns problemas e desafios da atuação na gestão do esporte, questionamos as motivações para permanecer no cargo de gestora (Quadro 13).

Quadro 13 - Categoria: motivação para permanecer na gestão

\begin{tabular}{|c|c|l|}
\hline Subcategoria & Unidade de Registro & \multicolumn{1}{c|}{ Unidade de Contexto } \\
\hline \multirow{2}{*}{$\begin{array}{c}\text { Motivação } \\
\text { intrínseca }\end{array}$} & $\begin{array}{c}\text { Apoiar o } \\
\text { desenvolvimento da } \\
\text { ginástica }\end{array}$ & $\begin{array}{l}\text { G1: "Tentar ajustar todos esses pontinhos que } \\
\text { eu acredito que tem como ajustar". }\end{array}$ \\
\cline { 2 - 4 } & Amor & $\begin{array}{l}\text { G2: "Mas é amor, até por querer ver o } \\
\text { crescimento delas (ginastas)". }\end{array}$ \\
\hline
\end{tabular}

Fonte: construção dos autores.

Tanto G1 quanto G2 apresentaram motivações de origem intrínseca que estão relacionadas ao desejo de contribuir com o desenvolvimento da ginástica e o amor, o qual está relacionado às atletas e à Ginástica. Ryan e Deci (2017) citam que a motivação intrínseca está relacionada à propensão inerente ao indivíduo em realizar determinada tarefa. $\mathrm{E}$, no discurso das gestoras, é perceptível que as recompensas e, por conseguinte, as motivações, estejam relacionadas à atividade em si, seja o prazer em sentir que está contribuindo para o esporte ou o amor pela Ginástica. 


\section{CONSIDERAÇÕES FINAIS}

Ao refletirmos sobre a gestão do esporte brasileiro, concordamos com Bastos (2003) que houve mudanças em termos organizacionais e administrativos. Isso é evidenciado por meio do desenvolvimento de algumas modalidades esportivas que só foram obtidos com a intervenção de uma gestão profissional. Mas, ainda conforme Bastos (2003), isso não é a regra. E, na compreensão de Mocsányi e Bastos (2005), a qualificação dos(as) gestores(as) esportivos(as) pode ser considerada um dos maiores problemas desse segmento, pois incide diretamente no trabalho dos(as) treinadores(as) e atletas.

No contexto capixaba, não observamos estudos que retratam a história da gestão das entidades esportivas e, mais especificamente, da FESG. Trata-se de uma lacuna que dificulta a análise dessa entidade e do contexto espírito-santense de gestão do esporte, pois impede uma verificação pormenorizada de possíveis avanços, estagnação ou retrocessos.

No decorrer do nosso estudo, foi possível evidenciar que a ausência de formação específica na área administrativa dificultou a realização exitosa das atividades inerentes à rotina da gestão federativa da Ginástica espírito-santense, o que tornou mais desafiador o planejamento, a organização, a execução e o controle das atividades. Ponderamos que é necessário que haja substituição do modelo de gestão das organizações brasileiras que possuem características amadoras por aquela centrada em profissionais qualificados na área, ou seja, que não esteja alicerçada na intervenção de ex-atletas, ex-praticantes, pais ou dirigentes sem formação específica.

No entanto, baseado nos resultados apresentados, ressaltamos que se não fosse pelo envolvimento das gestoras em questão com a ginástica, os desafios relatados poderiam ser ainda maiores. Isso nos motiva a pensar que apenas a qualificação profissional na área administrativa não seria suficiente para o desenvolvimento de uma gestão eficiente e que há necessidade de conhecimento do fenômeno esportivo e da sua influência na sociedade.

Podemos concluir que, para uma gestão eficaz, é necessário que haja tanto a formação específica, seja por meio da graduação ou de cursos preparatórios de formação continuada, quanto o engajamento com a modalidade a qual está sendo gerida. Acreditamos que a junção da qualificação na área administrativa e a afinidade pelo esporte somariam mais benefícios para a Ginástica capixaba, seja no âmbito dos(as) gestores(as), dos(as) treinadores(as) e, principalmente, dos(as) atletas. 
Em suma, esta pesquisa buscou trazer contribuições referentes a gestão da Ginástica no estado do Espírito Santo e, consequentemente, no Brasil. Principalmente, tendo em vista as lacunas de pesquisa apontadas nesta área e, em especial, relacionadas a Ginástica no país. Por fim, sugerimos que outras localidades do Brasil sejam investigadas e analisadas visando um melhor desenvolvimento das instituições que regem as modalidades gímnicas no país e o desenvolvimento da Ginástica como um todo.

\section{REFERÊNCIAS BIBLIOGRÁFICAS}

AMARAL, Cacilda Mendes dos Santos; BASTOS, Flávia da Cunha. O gestor esportivo no Brasil: revisão de publicações no país. Revista intercontinental de gestão desportiva, v. 5, n. 1, p. 68-78, 2015.

AZEVEDO, Paulo Henrique; BARROS, Jônatas de França; SUAIDEN, Samir. Caracterização do perfil do gestor esportivo dos clubes da primeira divisão de futebol do Distrito Federal e suas relações com a legislação esportiva brasileira. Revista da educação física, v. 15, n. 1, p. 3342, 2004.

BARDIN, Laurence. Análise de conteúdo. Lisboa, Portugal: Edições 70, 2011.

BARROS FILHO, Marcos Antônio e colaboradores. Perfil do gestor esportivo brasileiro: uma revisão de literatura. Revista intercontinental de gestão desportiva, v. 3, supl. 1, p. 44-52, 2013.

BARROS, José Arthur Fernandes; MAZZEI, Leandro Carlos. Gestão de clubes esportivos. In: MAZZEI, Leandro Carlos; BASTOS, Flávia da Cunha (Orgs.). Gestão do esporte no Brasil: desafios e perspectivas. São Paulo: Ícone, 2012.

BASTOS, Flávia da Cunha. Administração esportiva: área de estudo, pesquisa e perspectivas no Brasil. Motrivivência, n. 20-21, p. 295-306, 2003.

BASTOS, Flávia da Cunha; MAZZEI, Leandro Carlos. Gestão do Esporte no Brasil. In: VANCE, Patrícia de Salles; NASSIF, Vânia Maria Jorge; MASTERALEXIS, Lisa Pike. Gestão do Esporte: casos brasileiros e internacionais. São Paulo: LTC, 2015.

Organizações esportivas: conceitos, (des) entendimentos - propostas de modelo teórico unificado para o Brasil. Revista de gestão e negócios do esporte, v. 5, n. 2, p. 55-81, 2020.

BOUDENS, Emile. (CPI CBF/NIKE: textos e contexto VI) Estruturas esportivas. Brasília, DF: Câmara dos Deputados, 2002.

CAPINUSSÚ, José Maurício. Administração desportiva moderna. São Paulo: Ibrasa, 2002. 
CONFEDERAÇÃO BRASILEIRA DE GINÁSTICA. Final do brasileiro Caixa de ginástica rítmica comemora fortalecimento da modalidade. 2019. Disponível em: <https://www.cbginastica.com.br/noticia/1397/final-do-brasileiro-caixa-de-ginastica-ritmicacomemora-fortalecimento-da-modalidade>. Acesso em: 07 nov. 2019.

CASTRO, Lucio. Os negócios ocultos da Confederação Brasileira de Ginástica. 2021. Disponível em: <https://agenciasportlight.com.br/index.php/2021/08/20/os-negociosocultos-da-confederacao-brasileira-de-ginastica/> . Acesso em: 16 nov. 2021.

COMITÊ OLÍMPICO DO BRASIL. Programa de gestores. Disponível em: <https://www.cob.org.br/pt/cob/home/instituto-olimpico-brasileiro/programa-de-gestores>. Acesso em: 18 nov. 2021.

COSTA, Lamartine Pereira da. Diagnóstico da educação física/desportos no Brasil. Rio de Janeiro: Fename, 1971.

COUTO, Ana Cláudia Porfirio e colaboradores. Perfil do gestor esportivo: análise centrada na região metropolitana de Belo Horizonte. FIEP Bulletin, v. 81, p 1-5, 2011.

FEDERAÇÃO DO ESPÍRITO SANTO DE GINÁSTICA (FESG). Estatuto. Disponível em: <http://www.fesg.com.br/portal/images/phocadownload/estatuto\%20fesg\%20-

\%202015.pdf>. Acesso em: 09 dez. 2019.

GARCIA, Diego; VALENTE, Rafael. Ginástica teve equipamentos jogados em galpão, pagamentos duplicados e despesas fantasmas. 2017. Disponível em: <http://www.espn.com.br/noticia/662128_ginastica-teve-equipamentos-jogados-em-galpaopagamentos-duplicados-e-despesas-fantasmas>. Acesso em: 30 mai. 2017.

GOMES, Euza Maria Paiva. Esporte e inclusão social: mulheres na gestão esportiva brasileira. In: COSTA, Lamartine Pereira da. Atlas do esporte no Brasil: atlas do esporte, educação física e atividades físicas de saúde e lazer no Brasil. Rio de Janeiro: Shape, 2005.

GOMES, Manuel Álvaro Ferreira. Estratégia de desenvolvimento do associativismo desportivo: uma proposta para a quantificação do índice de satisfação do praticante. 2001. 182f. Dissertação (Mestrado em Ciência do Desporto). Universidade do Porto, Porto, Portugal, 2001.

HUMS, Mary A.; MACLEAN, Joanne. Governance and policy in sport organizations. Scottsdale, USA: Halcomb Hathaway, 2004.

ISAYAMA, Hélder Ferreira e colaboradores. Lazer, políticas públicas e formação profissional. In: ISAYAMA, Hélder Ferreira e colaboradores. Gestão de políticas de esporte e lazer. Belo Horizonte, MG: UFMG, 2011.

LIMA, Letícia Bartholomeu de Queiroz. Fatores que influenciam o sucesso esportivo internacional da ginástica artística feminina brasileira. 311f. 2020. Tese (Doutorado em 
Educação Física). Universidade Estadual de Campinas, Campinas, SP, 2020.

MAZZEI, Leandro Carlos; AMAYA, Katherine; BASTOS, Flávia da Cunha. Programas acadêmicos de graduação em gestão do esporte no Brasil. Revista mackenzie de educação física e esporte, v. 12, n. 1, p. 219-234, 2013.

MATTAR, Michel Fauze; MATTAR, Fauze Najib. Gestão de negócios esportivos. Rio de Janeiro: Elsevier, 2013.

MAZZEI, Leandro Carlos; BASTOS, Flávia da Cunha. Gestão do esporte no Brasil: desafios e perspectivas. In: MAZZEI, Leandro Carlos; BASTOS, Flávia da Cunha (Orgs.). Gestão do esporte no Brasil: desafios e perspectivas. São Paulo: Ícone, 2012.

MAZZEI, Leandro Carlos; BARROS, José Arthur Fernandes. Gestão de federações esportivas. In: MAZZEI, Leandro Carlos; BASTOS, Flávia da Cunha (Orgs.). Gestão do esporte no Brasil: desafios e perspectivas. São Paulo: Ícone, 2012.

MOCSÁNYI, Vinícius; BASTOS, Flávia da Cunha. Gestão de pessoas na administração esportiva: considerações sobre os principais processos. Revista mackenzie de educação física e esporte, v. 4, n. 4, p. 55-69, 2005.

MULLIN, Bernard J. Sport management: the nature and utility of the concept. Arena review, v. 4, n. 3, p. 1-11, 1980.

NOLASCO, Verônica Perisse e colaboradores. Administração/gestão esportiva. In: COSTA, Lamartine Pereira da (Org.). Atlas do esporte no Brasil. Rio de Janeiro: Shape, 2005.

OLIVEIRA, Maurício dos Santos. O panorama da ginástica artística masculina brasileira: um estudo histórico-crítico do período 2005-2008. 2010. 270f. Dissertação (Mestrado em Educação Física). Universidade Estadual de Campinas, Campinas, SP, 2010.

PARKHOUSE, Bonnie L. The management of sport: its foundation and application. 2. ed. St. Louis, USA: Mosby Year Book, 1996.

PIEKARZ, Mark. An overview of sport management. In: BILL, Karen (Org.). Sport management. Exeter, England: Learning Matters, 2009.

PIMENTA, Rogério da Costa. $\mathbf{O}$ perfil profissional do gestor de organizações esportivas brasileiras. 2001. 148f. Dissertação (Mestrado em Administração Pública). Fundação Getúlio Vargas, Rio de Janeiro, 2001.

PIRES, Gustavo Manuel Vaz Silva; LOPES, José Pedro Sarmento de Rebocho Lopes. Conceito de gestão do desporto: novos desafios, diferentes soluções. Revista portuguesa de ciências do desporto, v. 1, n. 1, p. 88-103, 2001. 
RIBEIRO, Marco Aurélio de Sá. Modelos de governança e organizações esportivas: uma análise das federações e confederações esportivas brasileiras. 2012. 136f. Tese (Doutorado em Administração). Fundação Getúlio Vargas, Rio de Janeiro, 2012.

RUBIO, Kátia. Mega eventos esportivos, legado e responsabilidade social. São Paulo: Casa do Psicólogo, 2007.

RYAN, Richard; DECl, Edward. Self-determination theory: basic psychological needs in motivation, development and wellness. New York, USA: Guilford, 2017.

VENTURA, Magda Maria. O estudo de caso como modalidade de pesquisa. Revista da sociedade brasileira de cardiologia, v. 20, n. 5, p. 383-386, 2007.

ZANATTA, Thaís Camargos e colaboradores. O perfil do gestor esportivo brasileiro: revisão sistemática da literatura. Movimento, v. 24, n. 1, p. 291-304, 2018.

\section{Dados da primeira autora:}

E-mail: isabela.christ@hotmail.com

Endereço: Centro de Educação Física e Desportos da UFES), Núcleo de Pesquisa em Ginástica - NPG, Avenida Fernando Ferrari, 514, Campus Universitário, Vitória, ES, CEP: 29075-810, Brasil.

Recebido em: 20/10/2021

Aprovado em: 29/11/2021

\section{Como citar este artigo:}

MAXIMO, Isabela Christ e colaboradores. O perfil das gestoras da federação do espírito santo de ginástica e as perspectivas acerca da sua gestão. Corpoconsciência, v. 25, n. 3, p. 147-167, set./ dez., 2021. 